\title{
CLASSIFICAÇÃO DE MARINHAS: UMA PROPOSTA DE METODOLOGIA COMPARATIVA
}

\author{
Francisco Eduardo Alves de Almeida' \\ Ricardo Pereira Cabral ${ }^{2}$
}

Uma das maiores dificuldades que os analistas navais se defrontam na atualidade é classificar as marinhas de guerra no mundo segundo seu poder relativo. Sendo uma análise relativa, que parâmetros considerar para essa comparação? Como definir qual meio de combate seria o mais poderoso? Algumas comparações são mais que evidentes e de fácil decisão. Sabe-se que um porta-aviões com seu grupo de aviação embarcado é mais poderoso que um navio-patrulha costeiro. Outra comparação de fácil decisão é a que defronta um submarino nuclear de ataque e um navio de abastecimento. As chances do último sobreviver são mínimas. Outras comparações, no entanto requerem maior cuidado. Entre um contratorpedeiro moderno dotado de sensores e mísseis contra um contratorpedeiros antiquado e dotado apenas de canhões, a razão nos leva a considerar que as chances para o primeiro sobreviver serão bem maiores em razão da tecnologia e da capacidade de pronta resposta. No entanto, em situações especiais, essa lógica pode ser questionada, por exemplo em águas interiores quando o mais poderoso for surpreendido, ainda em navegação de cruzeiro.

Para meios com capacidades semelhantes a comparação já fica mais

I Graduado em História pela UFRJ. Mestre e Doutor em História Comparada pela UFRJ. Professor do Programa de Pós-Graduação em Estudos Marítimos da Escola de Guerra Naval. Coordenador do Projeto "Classificação de Marinhas" inserido no Projeto Pró-Defesa III CAPES/ MD. Email : alves.almeida@marinha.mil.br

2 Graduado em História pela UGF. Mestre e Doutor em História Comparada pela UFRJ. Professor colaborador do Programa de Pós-Graduação em Estudos Marítimos da Escola de Guerra Naval. Membro do Projeto "Classificação de Marinhas" inserido no Projeto Pró-Defesa III CAPES/MD. Email: ricardopc@uol.com.br 
problemática. Qual meio seria o mais poderoso, uma fragata moderna dotada de tecnologia de ponta ou um submarino nuclear de ataque dos anos 90 ou mesmo de um submarino convencional com a tecnologia moderna? Outros fatores logicamente devem ser considerados que não apenas a tecnologia e o número de meios confrontantes. Entraria nessa confrontação a área geográfica, o nível de adestramento e outros fatores subjetivos que são de difícil avaliação .

Aumentando o universo da amostragem, em relação a comparação entre marinhas de guerra, quais parâmetros devem ser considerados? Somente o número de meios seria suficiente para indicar qual a marinha mais poderosa ? Por exemplo uma marinha dotada de ioo navios patrulha seria mais poderosa que uma dotada de apenas io contratorpedeiros ? Essas questões assumem maior gravidade ainda quando se traz ao problema a capacidade de um país se projetar e construir seus próprios meios de combate, de possuir maior tecnologia agregada a construção naval, de disponibilizar maiores recursos financeiros na preparação e utilização de seus navios de guerra para o cumprimento de suas missões e finalmente a capacidade de treinar seus tripulantes que guarnecem os seus meios de combate. Seria a tradição naval também um fator a ser considerado ? Sem essas definições e se possível mensurações relativas a comparação torna-se muito mais problemática.

O que se pretende com essa pesquisa é estabelecer parâmetros que possam ser "comparáveis" entre si, tendo como amostra os números e capacidades publicadas em periódicos e documentos oficiais ostensivos das marinhas de guerra atualmente em atividade no mundo. Como classificar as marinhas de guerra em relação ao seu poder de combate entre si ? Como estabelecer um ranking relativo de marinhas de combate, utilizando ferramentas que possam ser coletadas nessas fontes ostensivas (publicações e periódicos de acesso geral) para uma classificação geral de poder relativo? Esse é o problema a ser estudado nessa pesquisa. Ao se definir esses parâmetros pode-se acompanhar a evolução de determinado poder naval na região geográfica estudada e de que forma essa evolução estará ocorrendo. No caso do projeto Pró-Defesa, em que se estabelece cenários de segurança e defesa nas Américas, essa metodologia poderá contribuir para a análise de cenários navais e processos comparativos de forças navais regionais. A relevância de tal metodologia é evidente ao se hierarquizar poderes navais segundo seu poder relativo entre si em determinado espaço geográfico de poder envolvendo o mar.

$\mathrm{Na}$ atualidade existem disponíveis no universo digital alguns sítios que se especializaram em classificar as marinhas de guerra e neste caso não são incluídas as Guardas Costeiras, dentro de um ranking de poder relativo entre os países pesquisados. A principal agência digital classificadora é e Glo- 
bal Firepower (GFP) que em seu sítio especializado https://www.globalfirepower.com ${ }^{3}$ indica as IIo marinhas mais relevantes no tempo presente.

Tal iniciativa da GFP tem sido muito referenciada tanto no meio militar como no acadêmico como um sítio com credibilidade e penetração na área de defesa. Em que pese a sua importância, algumas incongruências podem ser logo percebidas. A mais relevante indica que as marinhas de guerra são classificadas em relação ao número de navios de guerra, o que introduz distorções consideráveis na avaliação comparativa entre essas forças armadas. Como exemplo, cita-se a classificação da Marinha norte-americana, que é sabidamente a de maior poder absoluto e relativo entre os seus pares, figurar nesse ranking em terceiro lugar, logo atrás da Coreia do Norte e da China que possuem maior número de meios, se confrontados com a norte-americana. Não se consideram os tipos de navios, capacidade de retaliação, armamento e vetor nuclear, capacidade industrial e financeira, dentre outros fatores que devem ser levados em consideração quando se confrontam navios e esquadras com tarefas semelhantes ou pelo menos afins.

Alguns pesquisadores relevantes no meio acadêmico também procuraram classificar as marinhas de guerra segundo sua abrangência geográfica e capacidade de projeção de poder. O primeiro a assim proceder foi Michael Morris (I988) que em I985 propôs uma tipologia de marinhas para distinguir as forças navais do chamado terceiro-mundo ou medianas que se diferenciariam das do mundo "desenvolvido" com maiores poderes navais. Chegou assim a seis níveis de poder naval, distinguindo marinhas regionais, sub-regionais, de defesa de área, costeiras, de vigilância e simbólicas, utilizando fatores quantitativos. Em nenhum momento foi estabelecida uma classificação relativa de poder entre as marinhas de guerra.

A classificação estabelecida por Eric Grove (I990) também tem sido também muito referenciada. Ele baseou-se em parte na classificação de Michael Morris e assim estabeleceu uma hierarquia a das marinhas de guerra, sem classificação relativa, com nove níveis, no entanto tal classificação baseou-se tão somente na "percepção" do autor, sem distingui-las comparativamente. Trata-se assim de uma análise qualitativa sem classificação comparativa e sem o estabelecimento de fatores quantitativos.

Uma outra classificação sem considerar a comparação entre marinhas é a de Hervé Coutau-Begarie (20I0) que apresenta uma tipologia semelhante a Eric Grove (I990), que se baseia também em “percepção” sem classificá-las entre si, mas apontando uma hierarquia por tarefas a serem cumpridas por essas marinhas. Para Coutau-Begarie (2010) as marinhas de guerra no mun-

3 Acesso em 8 de junho de 2018. 
do podem ser classificadas em seis diferentes níveis segundo o seu poder e capacidades.

Essas tipologias levaram em consideração aspectos qualitativos e no caso de Morris um aspecto quantitativo, sem apresentar um ranking de marinhas de guerra. Essa pesquisa procura estabelecer exatamente esse ranking.

Quanto a justificativa desta pesquisa, o resultado apresentado por essa investigação permitirá que se disponibilize uma metodologia de classificação relativa entre marinhas de guerra, utilizando parâmetros mensuráveis de cunho científico que estará disponível a todos os pesquisadores que trabalham com o tema naval.

Em resumo, o que se pretende com essa pesquisa é estabelecer uma metodologia para se classificar as marinhas de guerra do mundo em um ranking, segundo parâmetros mensuráveis. Para tal precisam ser definidos que parâmetros seriam comparados e o tipo de marinha que se está avaliando, segundo suas capacidades e tarefas.

Pretende-se dessa maneira discutir as principais classificações de marinhas segundo as percepções dos principais teóricos dos Estudos Marítimos na atualidade e em seguida apresentar as ambiguidades desses modelos teóricos. Em sequência será discutida a metodologia proposta e seus parâmetros balizadores que irão nortear a classificação relativa dos poderes navais. Por fim será apresentada a aplicação do modelo proposto no caso das marinhas das Américas, apresentando uma classificação comparativa e ranking de poder entre elas.

\section{Classificação de Marinhas, um problema a ser resolvido}

O primeiro modelo que se tornou referência como exemplo comparativo entre os poderes navais foi o chamado Modelo de Ciclos Longos de Poder Marítimo elaborado pelos professores George Modelski e William Thompson (1987) das Universidades de Washington e do Estado da Florida, respectivamente. Suas pesquisas foram publicadas no livro Sea Power in Global Politics. 1494-1993 no ano de I988 edição da Universidade de Washington.

O modelo proposto por Modelski/Thompson tinha o propósito de desenvolver um conjunto de dados numéricos, abarcando 500 anos, de 1494 a I993 de modo a analisar como o poder marítimo (com capacidade de alcance mundial) tinha sido distribuído, a intensidade dessa concentração de poder em um ou mais Estados e como esses graus de concentração tinham flutuado nesse período de tempo. Em nenhum momento esses pesquisadores tiveram a intenção de hierarquizar marinhas nos diferentes tempos históricos, mas 
tão somente explicar comparativamente os seus poderes relativos e como esses poderes tiveram a capacidade de usar e disputar a liderança mundial a partir do mar. (Modelski and Thompson 1987).

Ao estudarem a prevalência do poder marítimo nas relações internacionais Modelski e Thompson (1987) levantaram questões fundamentais. Eles verificaram que as condições de liderança mundial de determinado Estado e as causas e consequências das grandes guerras mundiais eram submetidas a regularidades que eram repetitivas, cíclicas e evolucionárias. Essas regularidades, mudanças e guerras mundiais os autores designaram de ciclos longos de política externa. Em sequência a pesquisa os autores indicaram existir cinco longos ciclos a partir de I494 até I993, com os seguintes poderes navais prevalentes: Longo Ciclo I - poder naval prevalente Portugal, poderes coadjuvantes - Espanha, Inglaterra e França, no período de I494 a I5I6; Longo Ciclo II- poder naval prevalente Holanda, poderes coadjuvantes- Inglaterra, França e Espanha, no período de I580 a I608; Longo Ciclo III- poder naval prevalente Grã-Bretanha, poderes coadjuvantes - Holanda, França, Espanha e Rússia no período de I688 a I7I3; Longo Ciclo IV- poder naval prevalenteGrã-Bretanha, poderes coadjuvantes - França, Rússia, Holanda e Espanha, no período de I792 a I8I5 e por fim o Longo Ciclo V - poder naval prevalente - Estados Unidos da América, (EUA) poderes coadjuvantes- Reino Unido, França, União das Repúblicas Socialistas Soviéticas (URSS), Alemanha e Japão no período de I9I4 a I945.

$\mathrm{Na}$ atualidade continua a existir um grande predomínio dos EUA. Em cada ano de cada ciclo foi estabelecido um percentual de poder para os principais atores navais apontados. Apenas como ilustração, em I509, durante o Longo Ciclo I Portugal congregava $68 \%$ do poder relativo entre os poderes navais do período, seguido da Espanha com 19\%, 8\% para a França e 4\% para a Inglaterra. No Longo Ciclo II no seu auge a Holanda em I608 obteve 51\% do poder relativo, seguido da Inglaterra com 31\% e a Espanha com I8\%, No Longo Ciclo III - a Grã-Bretanha no ano de I7I3 com 47\%, seguido da Holanda com $29 \%$ e a França com $25 \%$. No Longo Ciclo IV novamente a Grã-Bretanha em I808 com 44\%, seguido da França com 21\%, Rússia com I8\%, Espanha com I2\% e Holanda 4\%. No último ciclo em I945 observou-se os EUA com $50 \%$ de poder, seguido com $35 \%$ o Reino Unido, $7 \%$ da URSS ,5\% da França, e $2 \%$ do Japão. Em I990 os EUA atingiram a espetacular marca de quase 63\% do poder em comparação com os seus pares.

Esse modelo apresenta muitas fragilidades conceituais e metodológicas, no entanto para o escopo desta pesquisa o mais destacado é a sua incapacidade de hierarquizar os poderes navais dentro de uma classificação que congregue todos os poderes navais mundiais no período considerado. Ele se 
concentra nos três ou quatro principais poderes e as suas percentagens de poder relativo entre eles. Apesar dessa fragilidade, esses estudos procuraram comparar poderes navais nos diferentes tempos históricos utilizando metodologia quantitativa perceptível, embora nem sempre abrangente.

Uma segunda tentativa de se hierarquizar as marinhas de guerra no tempo presente foi proposta por Michael Morris em seu livro Expansion of Third World Navies publicado em I985, pela St Martin's Press que, concentrando-se nas marinhas do chamado terceiro mundo, distinguiu seis níveis a partir de uma análise essencialmente quantitativa, utilizando como parâmetros os chamados "grandes navios de combate". Para Morris as marinhas terceiro-mundistas poderiam ser dos seguintes níveis: Nível I - Marinhas Regionais, possuidoras de mais de 15 grandes navios de combate de superfície ou submarinos, possuidoras de todas as categorias de equipamentos militares incluída a aviação embarcada, com forte capacidade de defesa costeira e capacidade de projeção oceânica; Nível 2 - Marinhas Sub-regionais ou de Projeção Adjacente, possuidoras de mais de I5 grandes navios de combate de superfície ou submarinos, com a maior parte das categorias de equipamentos militares existentes excetuando a aviação embarcada, com forte capacidade de defesa costeira e capacidade limitada de projeção oceânica além da zona econômica exclusiva; Nível 3 - Marinhas de Defesa de Área - com 6 a I5 grandes navios de combate de superfície ou submarinos, possuindo várias categorias de equipamento militar, com forte defesa costeira limitada a zona econômica exclusiva; Nível 4- Marinhas Costeiras - de i a 5 grandes navios de combate de superfície ou submarinos com equipamentos militares em quantidade restrita e boa capacidade de defesa costeira e limitada projeção no interior da zona econômica exclusiva; Nível 5 - Marinhas de Vigilância - com nenhum grande navio, apenas navios-patrulha com capacidade de lançar mísseis e de patrulhar águas territoriais e por fim o Nível 6 - Marinhas simbólicas- sem navios patrulha, somente lanchas sem capacidade de controlar águas territoriais. (Morris I988)

Essa classificação embora pertinente em razão da inexistência de classificações que lhe façam contraponto, é frágil em diversos aspectos. Em primeiro lugar como classificar "marinhas do terceiro-mundo". O que significa essa classificação de países ? Que países compõem essa categoria ? Um segundo ponto, o que significa grandes navios de combate ? Seria um contratorpedeiro igual a um navio-tanque ? Ou quem sabe a uma corveta ? Seriam considerados grandes navios ? E como compará-los ? Teriam a mesma classificação ? E a efetiva capacidade para o combate ? E a capacidade logística para apoiá-los, não seria considerada ? A simplicidade do modelo o fragiliza, além do mais as percepções do que seja "boa capacidade de defesa costeira" poderá 
variar de analista para analista. O que vem a ser uma "capacidade de projeção oceânica”. Poderá ela ser mensurável ? Esses são pontos que prejudicam a aceitação do modelo de Morris como um fator classificador de marinhas. Por fim, não há a comparação relativa entre as marinhas de guerra, fato principal na condução da presente pesquisa.

Uma terceira proposta de classificação de marinhas foi idealizada por Hervé Coutau-Bégarie em seu livro Tratado de Estratégia, publicado pela Escola de Guerra Naval em parceria com a Diretoria de Patrimônio Histórico e Documentação da Marinha, no ano de 20Io. Nessa proposta, Coutau-Bégarie, inspirado na utilização de navios de linha a vela do modelo Modelski/Thompson, enquadrou as marinhas de combate em seis níveis a saber: I- Marinhas de io Nível - são as chamadas Marinhas Globais. Elas dispõem de todas as categorias de armamentos e equipamentos modernos, podendo cumprir todas as funções de dissuasão e de intervenção em qualquer local do mundo. Sua capacidade de retaliação é muito grande. Atualmente a única marinha que se encaixa nessa categoria é a Marinha norte-americana; 2- Marinhas de 20 Nível- são marinhas também com capacidade global, com força oceânica capaz de se apresentar em todos os oceanos, podendo intervir ocasionalmente além de seu ambiente regional. Coutau-Bégarie enquadra as Marinhas britânica, francesa e russa, no entanto por certo a chinesa já pode ser incluída nesse grupo; 3- Marinhas do 30 Nível- são marinhas regionais, sem capacidade de dissuasão nuclear com forte capacidade de operarem em teatro oceânico. Poderão ser marinhas sem porta-aviões, mas possuidoras de esquadras e submarinos abundantes e de boa qualidade e também de marinhas com porta-aviões apoiadas por respeitável esquadra. Coutau-Bégarie aponta para a existência 6 marinhas nessa categoria; 4- Marinhas de 40 Nível- são chamadas de sub-regionais com menos meios que as de 30 Nível, mas podendo intervir em alto-mar. Não possuem porta-aviões e possuem um número reduzido de navios de superfície ou submarinos. Muitas dessas marinhas adotam as chamadas compras de oportunidade o que as colocam em um plano inferior; 5- Marinhas de 50 Nível - são as marinhas costeiras, porém com boa capacidade militar, cada uma adaptada a um tipo de teatro e missões específicas. Como exemplo Coutau-Bégarie aponta a Marinha belga especializada em guerra de minas, além das Marinhas sueca e norueguesa capazes de dispor de eficientes submarinos modernos. Essas marinhas dispõem de poucos grandes navios de combate, mas são capazes de utilizar lanchas rápidas armadas com mísseis anti-navios, uma tendência na década de 70 em especial no que ele chamou de Terceiro Mundo; 6- Marinhas de Go Nível - são forças navais policiais sem potencial militar. Normalmente dispõem de lanchas, navios-patrulha, navios de contramedidas de minagem, podendo assegurar vigilância limitada em 
águas territoriais e na zona econômica exclusiva. (Coutau-Bégarie 2010)

Coutau-Bégarie (2010) aponta existirem ainda o que chamou de marinhas simbólicas cujos meios são irrisórios e mal conseguem controlar suas próprias águas territoriais. Servem, no entanto para representar a soberania estatal em área conflituosa.

Essa classificação, embora se esforce para ser mais qualitativa do que numérica como a de Morris, não indica como qualificar " com boa capacidade militar". O que seria isso ? Não especifica por quanto tempo de atuação. Além disso o que vem a ser "um número reduzido" de meios? Dois, cinco ou dez ? O que vem a ser "respeitável esquadra" ? Ele não definiu. O que vem a ser "poucos grandes navios de combate" ? Tampouco definiu. Além disso ele não hierarquiza essas marinhas, citando apenas algumas como integrantes de níveis sem identificar posição relativa.

Uma quarta proposta de classificação de marinhas foi apresentada por Eric Grove em seu livro The Future of Sea Power de I990, publicado pelo U.S Naval Institute. Grove dividiu as marinhas em ro níveis segundo sua importância em relação a seu poder mundial. Antes de apresentá-la ele mencionou a dificuldade em se conduzir uma classificação de marinhas em razão de se ter que levar em consideração o tipo de forças empregadas, a sofisticação de seus equipamentos e capacidade de manutenção de forças destacadas e a quantidade de meios disponíveis para pronto emprego. Grove (I990) pretendeu ir mais longe que Morris ao inserir na sua tipologia as Marinhas ditas do Terceiro Mundo e a de outros estratos, de modo a produzir um rank "hierárquico naval global".

Como Nível i o autor chamou de Grandes Marinhas com Força Global e Projeção de Poder Completa - que seriam as marinhas capazes de conduzir todas as tarefas militares navais em escala global. Nesse caso somente a Marinha norte-americana estaria nele inserido; Nível 2 - Grandes Marinhas com Força Global e Projeção de Poder Parcial - seriam marinhas capazes de conduzir a maioria das tarefas militares navais em escala global de forma parcial. Elas poderiam projetar poder longe de seu território de forma limitada tal como a antiga Marinha da URSS; Nível 3 - Médias Marinhas com Força Global e Projeção de Poder - seriam marinhas de capacidade média com capacidade de operar porta-aviões, unidades anfíbias, submarinos nucleares de ataque e balísticos e forças de superfície adequadas que poderiam conduzir uma grande operação fora de sua área de interesse. Nesse caso existiam as Marinhas do Reino Unido e França, podendo em médio e longo prazo serem incluídas as marinhas do Japão e China.

O Nível 4 - Médias Marinhas com Força Regional e Projeção de Poder que seriam marinhas capazes de projetar força em um teatro adjacente ao 
seu teatro de interesse estratégico. Compõem esse grupo, segundo Grove, a Índia, Japão, China, Itália, Holanda, Alemanha, Espanha, Bélgica, Canadá, Austrália, Brasil e Argentina; Nível 5 - Marinhas Adjacentes com Projeção de Poder- seriam marinhas com alguma possibilidade de projetar força afastado de suas costas. Estão incluídas nesse grupo Portugal, Grécia, Turquia, Chile, Peru, Israel, África do Sul, Coréias do Sul e do Norte, Taiwan, Paquistão, Nova Zelândia, Iran, Iraque e Arábia Saudita. Grove salientou que nenhuma dessas marinhas poderia conduzir operações navais de alto nível em grandes distâncias oceânicas; Nível 6 - Marinhas de Defesa Territorial Off shore são marinhas capazes de conduzir operações policiais e defensivas até 200 milhas de suas costas. Nesse grupo se incluem marinhas da Noruega, Dinamarca, Suécia, Polônia, Romênia, Bulgária, a antiga Iugoslávia, Argélia, Marrocos, Libia, Egito, Nigéria, Cuba, Colômbia, Equador, Venezuela, Bangladesh, Indonésia, Malásia, Tailândia e Filipinas. Elas possuem navios do tipo fragatas, grandes corvetas e alguma capacidade de submarinos; Nível 7 - Marinhas de Defesa Territorial Inshore- são marinhas capazes somente de defender suas águas territoriais utilizando lanchas armadas com mísseis, aviação de curto alcance e uma capacidade limitada de submarinos. Incluem-se nesse grupo marinhas da Albânia, Angola, Bahrain, Brunei, Camarões, Etiópia, Finlândia, Gabão, Quenia, Kuwaite, Iemen do Norte, Oman, Qatar, Somalia, Singapura, Iemen do Sul, Siria e Tunísia; Nível 8 - Marinhas Constabulares são marinhas que servem apenas para funções policiais, não possuindo mísseis e apenas armamento de pequeno calibre que poderiam ser Guardas-Costeiras. São incluídas nesse grupo as marinhas do México, República Dominicana, Uruguai, Islândia, Irlanda, Burma, Shri Lanka, Gana e Tanzânia. Por fim o Nível 9 - Marinhas Diminutas que possuem mínimas condições de capacidade de defesa com apenas uma organização formal e pequenas embarcações de patrulha. A maioria dos países pobres possuem Marinhas Diminutas. (Grove I990).

A classificação apresentada por Eric Grove é um avanço em relação as tipologias anteriores, pois além de classificá-las de modo mais preciso e abrangente, cita exemplos de marinhas que se encaixam nos seus diferentes nove níveis classificatórios. Trata-se da primeira classificação relativa de marinhas, embora não as hierarquize segundo poderes relativos. Essa tipologia poderá servir como referência para a proposição de uma nova classificação.

O sítio eletrônico https://www.globalfirepower.com publica anualmente uma classificação muito utilizada para comparar forças armadas no mundo. Trata-se de um eficiente referencial para quem quer acessar informações relevantes sobre os iıo países listados no seu ranking. O sítio leva em consideração informações atualizadas sobre a economia, características geográficas como fronteiras, espaço e população, orçamentos de defesa, den- 
tre muitos outros referenciais. Este sítio descreve de forma pormenorizada os números das forças armadas desses países e é capaz de comparar relativamente dois países. No que tange às marinhas o sítio apresenta um ranking comparativo entre esses serviços que embora de extrema utilidade para os pesquisadores não aponta com exatidão os poderes relativos entre essas forças navais. No ranking de 2017 é listada como a marinha número I a pertencente a Coréia do Norte por possuir maior número de meios que as mais poderosas Marinhas dos EUA e China. Esse indicador iguala um porta-aviões a um navio-patrulha, o que distorce a comparação totalmente. A Marinha dos EUA, reconhecidamente a mais poderosa do mundo, possui $4 \mathrm{I} 5$ meios e coloca-se no número 3 da escala, atrás da Coréia do Norte com 967 e China com 7I4 meios de combate. A Marinha do Brasil figura na posição 23 com IIo meios atrás de marinhas reconhecidamente de menor expressão com a boliviana, colombiana e a de Myamar.

Na apresentação do sítio é indicado que os números não diferenciam capacidade tecnológica, treinamento das tripulações e a qualidade dos meios apresentados. Assim como referencial comparativo entre marinhas ele não é satisfatório.

Segundo Geoffrey Till em seu Seapower a guide for the Twenty-First Century em sua segunda edição do ano de 2009, o ato de classificar marinhas é "difícil e perigoso ", no entanto existem pontos que podem ser levados em consideração para quem deseja organizar as marinhas e classificá-las segundo um critério objetivo, transparente e justo. (Till 2009, 99) Eles são os seguintes:

I- Tamanho e Natureza da Marinha no qual leva-se em consideração além dos números a capacidade de manter grandes navios de superfície;

2- Alcance Geográfico que seria a sua capacidade de operar afastado de sua própria costa;

3- Função e Capacidade que seria a sua função oceânica ou não e a sua capacidade de conduzir determinadas operações; çadas; e

4- Tecnologia que seria a capacidade de ter acesso a tecnologias avan-

5- Reputação que se traduziria no seu poder de dissuasão e a percepção que as outras marinhas têm dela. A essa característica estaria associada a sua experiência de combate.

Dessa forma pode-se deduzir que não existem classificações que reflitam efetivamente os poderes relativos entre as marinhas do mundo, sendo necessário estabelecer critérios quantitativos como qualitativos para uma classificação o mais próxima possível da realidade. 
Como fontes de referência foram utilizadas as publicações Jane's Fighting Ships, o próprio sítio https://www.globalfirepower.com, revistas especializadas como U.S Naval Proceedings, Naval Review e Naval Forces, assim como sítios da ONU, governamentais, e das próprias marinhas, de modo a se ter um banco de dados compatível e confiável para as comparações.

Pretende-se com essa classificação oferecer ao mundo acadêmico, empresarial e militar uma classificação que seja capaz de mensurar, relativamente, poderes navais dentro dos cenários internacional e regional de defesa e segurança. Para isso serão utilizadas fontes ostensivas com parâmetros a serem determinados e ponderados segundo pesos específicos. Alguns fatores, no entanto, devem ser definidos para o estabelecimento de uma metodologia consistente, quais sejam que tipos de alcance deve ser cada uma das marinhas de guerra analisadas, segundo suas capacidades, interesses e projeção? Que parâmetros devem ser quantificados, levando-se em consideração determinantes que interessam ao poder naval de cada estado como fatores importantes para a medição de poder relativo entre forças navais ? Quais os pesos específicos para cada parâmetro estabelecido levando-os em consideração como medições do poder relativo entre forças navais? Como hierarquizar as marinhas de guerra mundiais segundo um sistema de pontuação de $\circ$ a Io०, segundo os pesos específicos estabelecidos, iniciando-se na mais poderosa até a menos poderosa?

\section{Metodologia de Classificação de Marinhas}

A metodologia empregada foi a comparativa utilizando indicadores econômicos e militares tendo como referência publicações abertas e conceituadas no meio naval. A comparação se expressou em requisitos necessários para comparar poderes navais tais como capacidade tecnológica, quantidade de meios e experiência de combate dentre alguns. Como não se pode confrontar requisitos distintos como quantidade de meios e recursos naturais utilizou-se a sistemática de pesos na qual os requisitos mais importantes teriam maiores pesos, enquanto os menores teriam menores pesos. Dependendo do tipo de parâmetro apontado, privilegiou-se a avaliação quantitativa quando foi possível estabelecer valores numéricos para a comparação. Em outros casos como por exemplo a "mentalidade marítima", privilegiou-se a avaliação qualitativa por ser difícil quantificar a mentalidade. Essa avaliação ocorreu por meio de debates no Grupo de Controle ${ }^{4}$ segundo os onze parâmetros esco-

4 Grupo de Controle refere-se a uma equipe de investigação a qual competiu a escolha dos parâmetros selecionados, dos pesos relativos e das discussões de condução da pesquisa. Ele foi conduzido 
lhidos e depois mensurados por pesos. Os parâmetros escolhidos foram avaliados em termos quantitativos e quando impossível em termos qualitativos. Foi estabelecido o peso I (um) como valor mínimo e peso 4 ( quatro) como valor máximo. Os onze parâmetros comparativos selecionados e seus pesos específicos foram os seguintes:

I- Número de meios - peso 2 - análise quantitativa e qualitativa. Sempre que necessário e quando existiam referências para tal, procurou-se analisar além do número de meios a capacidade de aprestamento 5 dos navios.

2- Tipos de meios existentes - peso 4 - análise quantitativa e quantitativa. Esse peso deveu-se a diferenciar um porta-aviões de um navio patrulha, atribuindo maior peso ao primeiro do que ao segundo. Sempre que possível procurou-se analisar o nível de treinamento do meio considerado como um conjunto navio e tripulação.

3- Efetivos Navais - peso I - análise quantitativa. Esse baixo peso relativo considera apenas os efetivos navais sem a análise de seu treinamento.

4- Razão Efetivos Navais/População - peso I - análise quantitativa. Esse número reflete o percentual da população envolvida com as lides navais.

5- Bases e Estaleiros - peso 2 - análise quantitativa e qualitativa. Esse parâmetro refere-se a capacidade logística de um país apoiar seus meios navais em reparos e manutenção.

6- Nível Tecnológico - peso 4 - análise qualitativa. Esse parâmetro refere-se ao nível tecnológico de determinado país e de sua Marinha de combate. Como esse parâmetro é de difícil mensuração e dependente de diversos fatores sua análise será qualitativa.

7- Capacidade Nuclear - peso 2 - análise qualitativa. Esse parâmetro refere-se a capacidade de um país dominar o ciclo nuclear e de utilizar essa energia em proveito da Marinha.

8- Experiência de Combate - peso I - análise qualitativa. Esse parâmetro refere-se a atuação de sua Marinha em operações reais de combate.

9- Capacidade Financeira - peso 4 - análise quantitativa e qualitativa. Esse parâmetro refere-se a capacidade de um estado manter seus navios em condições de prontidão eficiente e eficaz, tendo como referência o Produto Interno Bruto (PIB).

pelos dois autores deste artigo com alunos de mestrado do Programa de Pós-graduação em Estu-
dos Marítimos da Escola de Guerra Naval, dentro do escopo do Projeto Pró-Defesa III. Além disso
dois dos membros do Grupo são oficiais de marinha com reconhecido conhecimento no campo
naval e ex-comandantes de unidades da Marinha de Guerra com muitos anos de operação no mar.
5 O aprestamento refere-se a capacidade de um meio naval estar disponível e pronto para o
combate considerando o adestramento de sua tripulação e sua plena disponibilidade material.

24 Austral: Revista Brasileira de Estratégia e Relações Internacionais v.7, n.14, Jul./Dez. 2018 
Io- Recursos Naturais - peso I - análise quantitativa e qualitativa. Esse parâmetro refere-se a capacidade de um estado em explorar seus recursos naturais em prol do fortalecimento de seu poder naval. Está ligado a outros parâmetros já apresentados.

II- Capacidade de construção naval - peso 3 - análise quantitativa e qualitativa. Esse parâmetro reflete a capacidade de um estado construir seus próprios navios de combate e de exportar para outros estados. Nesse parâmetro insere-se a produção de armamento, sensores e munição próprios. Está ligado a outros parâmetros apresentados.

A partir do que foi apresentado tem-se 25 pesos distribuídos em ir parâmetros a serem mensurados. Cada peso de cada parâmetro deverá ser multiplicado pelo nível no qual cada parâmetro deverá ser medido e multiplicado, indo de $\circ$ até 4, O nível o corresponde "a não ter nenhuma capacidade"; 0.5 corresponde a ter "mínima capacidade"; r,o corresponde a ter "pequena capacidade"; I, 5 corresponde a ter "de pequena a boa capacidade"; 2 , o corresponde a ter "boa capacidade"; 2,5 corresponde a ter "de boa a muito boa capacidade"; 3,0 corresponde a ter " muito boa capacidade"; 3,5 corresponde a ter "muito boa a excelente capacidade" e 4,0 a ter "excelente capacidade".

Assim para cada parâmetro apresentado corresponderá um valor numérico que retratará a capacidade do país naquele item específico. Por exemplo um estado que tenha uma boa capacidade de construção naval ( peso 3 ) terá como indicador numérico para esse item 3 × $2=6$. Se o Grupo de Controle considerar que a capacidade de construção naval do país seja de boa a muito boa ter-se-á 3 × 2,5 = 7,5 pontos.

Dessa maneira ter-se-á os valores máximos de cada parâmetro assim enunciados: Número de meios ( 2 x $4=8$ ); Tipos de meios ( 4 × 4 = I6); Efetivos Navais ( I x $4=4$ ); Razão Efetivos/População ( I x4 = 4); Nível Tecnológico ( 4 × $4=\mathrm{I} 6$ ); Bases e Estaleiros ( $2 \times 4=8$ ), Capacidade Nuclear ( $2 \times 4=$ 8 ); Experiência de Combate ( I x $4=4$ ); Capacidade Financeira ( 4 × $4=16$ ); Recursos Naturais ( I x $4=4$ ); Capacidade de Construção Naval ( 3 x $4=$ I2 ). Percebe-se assim que os parâmetros considerados mais relevantes foram os Tipos de Meios, Nível Tecnológico e Capacidade Financeira, todos com peso 4 e os parâmetros menos relevantes foram Efetivos Navais, Razão Efetivos/ População, Experiência de Combate e Recursos Naturais, todos com peso I. A máxima pontuação ocorrerá com ıoo pontos. A mínima com o ponto. Ao final os poderes navais serão classificados segundo uma classificação decrescente que irá de o a Ioo pontos em ordem do menor poder naval para o maior poder naval avaliado.

O cunho científico da pesquisa consiste na identificação dos valores pertinentes a cada parâmetro para cada poder naval analisado, com avaliações 
quantitativas e qualitativas pelo Grupo de Controle. Nota-se que as avaliações dos pesos são fatores subjetivos e passíveis de interpretações diversas, no entanto na inexistência de avaliação mais precisa no universo acadêmico, tal metodologia pretende se aproximar da realidade existente no tempo atual. Para avaliadores dos pesos constituiu-se o Grupo de Controle com oficiais de marinha, acadêmicos, jornalistas e especialistas na área de defesa.

Para cada parâmetro dependente de quantificação será utilizada a seguinte referência numérica:

\section{I - Número de meios}

\begin{tabular}{|l|l|}
\hline Pontoa & Parâmetro \\
\hline 0 & A marinha observada não possui meios contabilizados \\
\hline 0,5 & Possui entre 1 e 5 meios contabilizados \\
\hline 1,0 & Possui entre 5 e 39 meios contabilizados \\
\hline 2,0 & Possui entre 40 e 89 meios contabilizados \\
\hline 3,0 & Possui entre 90 e 349 meios contabilizados \\
\hline 4,0 & Possui mais de 350 meios contabilizados \\
\hline
\end{tabular}

Nesse parâmetro realizou-se um levantamento do número de meios, computando navios de combate e de apoio componentes das forças navais do país analisado. Não se considerou na pesquisa as Guardas Costeiras, somente as Marinhas de Guerra. Esses valores de meios contabilizados foram discutidos pelo Grupo de Controle levantando-se em consideração os atuais efetivos navais disponíveis ( 2016 ) e sua projeção comparativa média de cada nível. O peso para este parâmetro é 2 .

\section{2 - Tipos de Meios}

Levou-se em consideração a capacidade de cada meio e sua projeção de poder, segundo seu poder unitário médio. Por exemplo o porta-aviões nuclear possui uma numeração I5, enquanto uma corveta possui numeração 3. Isso não significa necessariamente dizer que o porta-aviões nuclear é cinco vezes mais poderoso que a corveta, pois esse "fator" é difícil de ser mensurado, uma vez que irá depender de sua prontidão para o combate, adestramento da tripulação, disponibilidade de ala aérea, enfim fatores de difícil contabilização. Não se levou em consideração a idade nem a capacidade de combate de cada meio 
já que o parâmetro 6 (Nível Tecnológico) avaliará a capacidade de tecnologia dos meios disponíveis a cada Marinha avaliada. O que se pode dizer a priori é que levou-se em consideração um fator numérico para definir o valor relativo de um meio de combate mais poderoso, no caso o valor is e para um meio mais modesto como uma corveta o valor 3. Trata-se assim de uma indicação apriorística inicial de um valor perceptível pelo Grupo de Controle. O peso para este parâmetro é 4 .

O que se faz nesse parâmetro é a multiplicação das numerações apontados pelo número de meios disponíveis em uma Marinha. Por exemplo uma Marinha que tenha I porta-aviões convencional, um cruzador convencional e 4 fragatas terá como numeração os valores IO x I +5 x I +4 x $4=3$ I pontos. A tabela de tipos de meios e pontos encontra-se indicada abaixo:

\begin{tabular}{|l|l|}
\hline Tipo de Meio & Pontos do Meio \\
\hline PORTA AVIÕES NUCLEAR & 15 \\
\hline PORTA AVIÕES CONVENCIONAL & 10 \\
\hline NAVIO DE ASSALTO ANFIBIO & 8 \\
\hline PORTA HELICÓPTEROS & 8 \\
\hline SUBMARINO NUCLEAR BALÍSTICO & 13 \\
\hline SUBMARINO NUCLEAR DE ATAQUE & 9 \\
\hline SUBMARINO CONVENCIONAL OCEÂNICO & 6 \\
\hline SUBMARINO CONVENCIONAL COSTEIRO & 4 \\
\hline CRUZADOR NUCLEAR & 7 \\
\hline CRUZADOR CONVENCIONAL & 5 \\
\hline DESTROYER/CT & 4 \\
\hline FRAGATAS & 4 \\
\hline CORVETA & 3 \\
\hline NAVIO - PATRULHA OCEÂNICO & 0,75 \\
\hline NAVIO PATRULHA & 0,25 \\
\hline NAVIO CAÇA MINAS & 1 \\
\hline NAVIO VARREDOR & 0,5 \\
\hline NAVIO DE APOIO LOGÍSTICO & 3 \\
\hline NAVIO DE DESEMBARQUE & 4,5 \\
\hline
\end{tabular}




\begin{tabular}{|l|l|}
\hline $\begin{array}{l}\text { NAVIOS AUXILIARES (+ HOSPITAL, COMAN- } \\
\text { DO, SALVATAGEM, REBOCADORES) }\end{array}$ & 1 \\
\hline $\begin{array}{l}\text { OUTROS (PESQUISA, ESCOLA, HIDROCEANO- } \\
\text { GRÁFICO) }\end{array}$ & 0,5 \\
\hline
\end{tabular}

Para efeito de somatório geral de pontos neste parâmetro foi observada a tabela abaixo que descreve a relação existente entre os somatórios parciais de cada marinha pesquisada e a pontuação estabelecida de o a 4. Dessa relação saiu o fator a ser multiplicado final desse parâmetro:

\begin{tabular}{|l|l|}
\hline Pontos & Parâmetro \\
\hline 0 & Possui até 5 pontos contabilizados \\
\hline 0,5 & Possui entre 6 e 20 pontos contabilizados \\
\hline 1,0 & Possui entre 21 e 50 pontos contabilizados \\
\hline 1,5 & Possui entre 51 e 75 pontos contabilizados \\
\hline 2,0 & Possui entre 76 e 150 pontos contabilizados \\
\hline 2,5 & Possui entre 151 e 500 pontos contabilizados \\
\hline 3,0 & Possui entre 501 e 800 pontos contabilizados \\
\hline 3,5 & Possui entre 801 e 999 pontos contabilizados \\
\hline 4,0 & Possui mais de 1000 (mil) pontos contabilizados \\
\hline
\end{tabular}

Como um exemplo prático dessa operação tem-se o que se segue para a marinha de combate composta de I porta-aviões convencional, I cruzador convencional e 4 fragatas, totalizando 3I pontos como anteriormente apontado. Se essa marinha ainda possuir io navios patrulha e 2 rebocadores possuirá como somatório total o seguinte: 3I pontos do resultado anterior e mais Io x 0,25 e 2 x I que somará 4,5 pontos. Ter-se-á o somatório final de 35,5 pontos que na tabela acima corresponderá a I ponto no somatório geral. Esse ponto multiplicado pelo peso 4 corresponderá a 4 pontos no somatório total.

\section{3 - Efetivos Navais}

Neste parâmetro contabiliza-se o efetivo constante de cada Marinha de guerra sem considerar aspectos relativos ao adestramento, número de meios e aprestamento para o combate. Tal parâmetro identifica a quantidade de indivíduos que compõem o poder naval do Estado. O Corpo de Fuzileiros Navais 
é incluído nesse efetivo, se for estabelecida pela Marinha a sua inclusão no efetivo final. Utiliza-se a tabela numérica abaixo, com peso I.

\begin{tabular}{|l|l|}
\hline Pontos & Parâmetro \\
\hline 0 & Efetivo naval total observado soma menos de 1000 indivíduos \\
\hline 0,5 & Efetivo naval total observado soma entre 1.001 e 5.000 indivíduos \\
\hline 1,0 & Efetivo naval total observado soma entre 5.001 e 15.000 indivíduos \\
\hline 1,5 & Efetivo naval total observado soma entre 15.001 e 30.000 indivíduos \\
\hline 2,0 & Efetivo naval total observado soma entre 30.001 e 50.000 indivíduos \\
\hline 2,5 & Efetivo naval total observado soma entre 50.001 e 100.000 indivíduos \\
\hline 3,0 & Efetivo naval total observado soma entre 100.001 e 200.000 indivíduos \\
\hline 3,5 & Efetivo naval total observado soma entre 200.001 e 500.000 indivíduos \\
\hline 4,0 & Efetivo naval total observado soma mais de 500.001 indivíduos \\
\hline
\end{tabular}

O Grupo de Controle considerou que efetivos abaixo de r.০oo indivíduos seriam inexpressivos. Dessa maneira, como exemplo teríamos uma Marinha com I6.000 homens com um fator multiplicador de I,5. A pontuação final seria $\mathrm{I}, 5 \mathrm{x}$ peso $\mathrm{I}=\mathrm{I}, 5$ pontos.

\section{4 - Razão Efetivos Navais/População}

Esse parâmetro tem o propósito de verificar a inserção da mentalidade marítima ${ }^{6}$ na população de determinado Estado. Parte-se do princípio que se o percentual de indivíduos ligados ao poder naval for alto, existirá uma aceitação natural com as demandas da Marinha de guerra e mais próximas serão as pessoas do mar. Sabe-se que esse parâmetro é passível de contestação, no entanto, sem dúvida quanto maior o percentual ligado ao mar maior a consciência da população de que o mar é importante. O cálculo será o número de habitantes dividido pelos efetivos navais do Estado. Há uma correlação direta com o parâmetro anterior. Será considerado peso I.

\footnotetext{
6 Mentalidade marítima refere-se a identificação que determinada sociedade tem em relação ao mar. É um parâmetro baseado em percepção qualitativa do Grupo de Controle e é um dos fatores amplamente debatido no livro "The Influence of Sea Power upon History, I66oI783" de Alfred Thayer Mahan, um clássico sobre os elementos do poder marítimo de I89o.
} 


\begin{tabular}{|l|l|}
\hline Pontos & Parâmetro \\
\hline 0 & Razão observada superior a10.001 habitantes por 01 (um) efetivo naval \\
\hline 0,5 & Razão observada entre 4.501 e 10.000 habitantes por 01 (um) efetivo naval \\
\hline 1,0 & Razão observada entre 3.501 e 4.500 habitantes por 01 (um) efetivo naval \\
\hline 1,5 & Razão observada entre 3.001 e 3.500 habitantes por 01 (um) efetivo naval \\
\hline 2,0 & Razão observada entre 2.501 e 3.000 habitantes por 01 (um) efetivo naval \\
\hline 2,5 & Razão observada entre 2.001 e 2.500 habitantes por 01 (um) efetivo naval \\
\hline 3,0 & Razão observada entre 1.501 e 2.000 habitantes por 01 (um) efetivo naval \\
\hline 3,5 & Razão observada entre 1.001 e 1.500 habitantes por 01 (um) efetivo naval \\
\hline 4,0 & Razão observada inferior a 1.000 habitantes por 01 (um) efetivo naval \\
\hline
\end{tabular}

\section{5 - Bases e Estaleiros}

Este parâmetro avalia a capacidade de uma Marinha prover apoio logístico para os seus navios por meio de bases navais e estaleiros capazes de repará-los. Trata-se assim de um elemento fundamental para se medir a capacidade logística de uma Marinha de combate. Quanto maior for o número de bases e estaleiros mais capacitada estará a Marinha para apoiar forças navais próximo de suas costas ou em regiões afastadas. É um dos parâmetros apontados por Alfred Mahan em sua formulação dos elementos do poder marítimo. O peso deste parâmetro é 2 .

\begin{tabular}{|l|l|}
\hline Pontos & Parâmetro \\
\hline 0 & Nenhuma base e/ou estaleiro contabilizado \\
\hline 1,0 & Entre 1 e 2 bases e/ou estaleiros contabilizados \\
\hline 2,0 & Entre 3 e 6 bases e/ou estaleiros contabilizados \\
\hline 3,0 & Entre 7 e 10 bases e/ou estaleiros contabilizados \\
\hline 4,0 & Mais de 11 bases e/ou estaleiros contabilizados \\
\hline
\end{tabular}

\section{6 - Nível Tecnológico}

Trata-se de uma avaliação empírica qualitativa, no entanto alguns elementos foram considerados para o estabelecimento deste parâmetro. Foram levados em consideração a capacidade de dispor de navios com propulsão nuclear que requer um maior nível tecnológico do que o convencional que a priori requer menores níveis . Em um segundo ponto o tipo de mísseis que seus meios são capazes de transportar e operar. Em ordem de sofisticação 
iniciou-se com mísseis de defesa de ponto, depois de área, mísseis de cruzeiro de médio alcance e longo alcance e balístico. O peso deste parâmetro por sua importância foi estabelecido como 4 .

\begin{tabular}{|l|l|}
\hline Pontos & Parâmetro \\
\hline 0 & Sem meios de poder naval \\
\hline 0,5 & Opera embarcação costeira com pouca tecnologia embarcada \\
\hline 1,0 & Opera meio com propulsão convencional e defesa de ponto \\
\hline 1,5 & Opera meio com propulsão convencional e defesa de área \\
\hline 2,0 & $\begin{array}{l}\text { Opera meio com propulsão convencional e míssil de cruzeiro de médio } \\
\text { alcance }\end{array}$ \\
\hline 2,5 & $\begin{array}{l}\text { Opera meios com propulsão convencional e míssil de cruzeiro de longo } \\
\text { alcance }\end{array}$ \\
\hline 3,0 & Opera meio com propulsão nuclear \\
\hline 3,5 & Opera meio com propulsão nuclear e míssil de cruzeiro \\
\hline 4,0 & Opera meio com propulsão nuclear e míssil balístico \\
\hline
\end{tabular}

\section{7 - Capacidade Nuclear}

Trata-se de um parâmetro importante para a mensuração de um poder naval. A marinha que tem capacidade de dominar a tecnologia nuclear de propulsão e transportar artefatos nucleares tem um poder de dissuasão que se diferencia das demais. Poderão existir classificações intermediárias para esse parâmetro. Por exemplo a Índia que possui capacidade de dominar o ciclo atômico e está desenvolvendo seu submarino de propulsão nuclear porém não possui a mesma capacidade plena como os Estados Unidos da América, mas está em processo de aquisição de capacidade. O peso estabelecido para esse parâmetro é 2 .

\begin{tabular}{|l|l|}
\hline Ponto & Parâmetro \\
\hline 0 & Não tem domínio de tecnologia de propulsão e artefatos nucleares \\
\hline 2,0 & $\begin{array}{l}\text { Possui domínio de tecnologia nuclear porém não possui meios de propul- } \\
\text { são atômica }\end{array}$ \\
\hline 3,0 & $\begin{array}{l}\text { Possui domínio de tecnologia nuclear e meios com propulsão atômica ,no } \\
\text { entanto não possui artefatos. }\end{array}$ \\
\hline 4,0 & Possui domínio pleno da tecnologia e artefatos nucleares \\
\hline
\end{tabular}




\section{8 - Experiência de Combate}

Trata-se de se verificar se o Estado esteve envolvido em um conflito com o uso do poder naval nos últimos 70 anos, isto é pós-Segunda Guerra Mundial, tempo em que se acredita que a experiência possa ser passada para gerações que se seguem. Levou-se em consideração a capacidade de um país integrar operações de paz com meios navais e de se ter envolvido em conflitos regionais e extra-regionais com pequenos, médios e grandes efetivos. O peso para este parâmetro será I.

\begin{tabular}{|l|l|}
\hline Pontos & Parâmetro \\
\hline 0 & Sem experiência de combate \\
\hline 1,0 & Possui experiência em operações de Imposição de Paz \\
\hline 2,0 & Possui experiência em Guerras regionais (em relação à localização do país) \\
\hline 3,0 & Possui experiência emGuerras extra-regionais médios e pequenos e efetivos \\
\hline 4,0 & Possui experiência emGuerra extra-regionais com grandes efetivos \\
\hline
\end{tabular}

\section{9 - Capacidade Financeira em relação a seu Produto Interno Bruto}

Para este parâmetro utilizou-se o fator Produto Interno Bruto (PIB) que indica a capacidade de um país gerar riqueza em suas transações. Embora o PIB por si não indique maior pujança financeira, ele poderá indicar a capacidade que um Estado tem de gerar recursos para desenvolver o seu poder naval em caso de necessidade. Teoricamente quanto maior o PIB maior capacidade terá o Estado em patrocinar a sua Marinha de combate. O peso estabelecido para este parâmetro é 4. Não foi considerado os orçamentos de Defesa pois muitos deles trazem embutidos o pagamento de pessoal e outras atividades não afetas à Defesa.

\begin{tabular}{|l|l|}
\hline Pontos & Parâmetro \\
\hline 0 & PIB inferior a U\$ 30 bilhões \\
\hline 1,0 & PIB observado entre U\$ 30 Bi e U\$ 200 Bi \\
\hline 2,0 & PIB observado entre U\$ 200 Bi e U\$ 1 Trilhão \\
\hline 3,0 & PIB observado entre U\$ 1 Tri e U\$ 3 Tri \\
\hline 4,0 & PIB observado superior a U\$ 3 Trilhões \\
\hline
\end{tabular}




\section{IO - Recursos Naturais considerando a produção de petróleo}

Levou-se em consideração para este parâmetro a produção diária de petróleo. O petróleo é o elemento fundamental para a manutenção de um poder naval com credibilidade. Em caso de conflito a capacidade de um estado produzir petróleo para o seu próprio uso será primordial. O peso para este parâmetro é I.

\begin{tabular}{|l|l|}
\hline Pontos & Parâmetro \\
\hline 0 & Sem reservas comprovadas ou exploração de petróleo \\
\hline 0,5 & Até $250,000 \mathrm{bbl} /$ day \\
\hline 1,0 & Entre 250,000 e $500,000 \mathrm{bbl} /$ day \\
\hline 1,5 & Entre 500,000 até $1.000,000 \mathrm{bbl} /$ day \\
\hline 2,0 & Entre $1.000,000$ até $2,000,000 \mathrm{bbl} /$ day \\
\hline 2,5 & Entre $2,000,000$ até $5,000,000 \mathrm{bbl} /$ day \\
\hline 3,0 & Entre $5,000,000$ até $8,000,000 \mathrm{bbl} /$ day \\
\hline 3,5 & Entre $8,000,000$, até $10.000 .000 \mathrm{bbl} /$ day \\
\hline 4,0 & Mais de $10,000,000 \mathrm{bbl} /$ day \\
\hline
\end{tabular}

\section{II - Capacidade de Construção Naval}

Neste parâmetro será considerado a capacidade de construção naval autóctone. Será considerado a capacidade de construir embarcações, navios de combate oceânicos e submarinos. O peso para este parâmetro é 3 .

\begin{tabular}{|l|l|}
\hline Pontos & Parâmetro \\
\hline 0 & Não constrói meio naval relevante \\
\hline 1,0 & Produz navios e embarcações costeiras \\
\hline 2,0 & $\begin{array}{l}\text { Capacidade de construção de Submarinos Convencionais e/ou Navios de } \\
\text { Superfície Oceânicos }\end{array}$ \\
\hline 3,0 & $\begin{array}{l}\text { Capacidade de Construção de Submarinos Nucleares e/ou grandes Navios } \\
\text { de Superfície }\end{array}$ \\
\hline 4,0 & $\begin{array}{l}\text { Capacidade de construção de Submarinos Nucleares balísticos e/ou NAe's } \\
\text { nucleares }\end{array}$ \\
\hline
\end{tabular}

De posse desses onze parâmetros métricos com os seus pesos específicos já se poderá preparar uma classificação de Marinhas por ordem da mais poderosa até a menos potente. Essa numeração em nenhum momen- 
to estabelecerá que uma Marinha com 90 pontos seja duas vezes superior que uma Marinha com 45 pontos. Essa numeração tão somente hierarquiza as Marinhas segundo uma pontuação sem correlação com poderio, somente com posição relativa na tabela final por área geográfica.

Essa investigação pretende hierarquizar essas marinhas de modo mais preciso que as existentes atualmente que levam somente em consideração a questão qualitativa. Procurou-se utilizar parâmetros numéricos hierarquizados como um fator mais próximo da realidade em termos de poder relativo.

Ao se determinar uma hierarquia procurou-se correlacionar essa listagem de poder relativo com uma tipologia qualitativa em relação ao alcance geográfico de cada poder naval avaliado. A tabela a ser complemento a listagem numérica está apontada abaixo:

Nível Io - Poder Naval com Alcance Global e com Projeção de poder total.

Nível 9- Poder Naval com Alcance Global com projeção de poder parcial.

Nível 8 - Poder Naval com Alcance Global sem projeção de poder.

Nível 7 - Poder Naval Regional com Projeção de poder total na região.

Nível 6- Poder Naval Regional com Projeção de poder parcial na região.

Nível 5- Poder Naval Regional sem projeção de poder.

Nível 4- Poder Naval Local com projeção de poder total em seu território.

Nível 3- Poder Naval Local com projeção de poder parcial em seu território.

Nível 2- Poder Naval Local sem projeção de poder.

Nível I- Poder Naval Constabular ou Policial.

Essa avaliação é totalmente qualitativa e é apresentada depois de análise do Grupo de Controle. Desse modo poderão ser apresentadas a hierarquização por poder de cada marinha de guerra em determinado ambiente geográfico sob o ponto de vista quantitativo e em seguida indicar o nível em que cada poder naval se posiciona, tendo essa avaliação um cunho eminentemente qualitativo. Essa classificação por níveis baseou-se na formulada por Eric Grove.

No caso de igualdade de pontos entre duas marinhas avaliadas será utilizado como critério de desempate o alcance geográfico por níveis como apontado acima, sendo o de maior poder o nível io ( Poder Naval com Alcance Global e com Projeção de poder total) e o de menor poder o Poder Naval Constabular ou Policial. 


\section{0 caso das Américas e a aplicação do modelo}

Tomando como referência as marinhas das Américas, chega-se a um total de quinze países que possuem forças navais constituídas. A Marinha dos Estados Unidos da América sobressai, como era esperado, como a mais poderosa no continente americano. Sua posição é a de número um com 99 pontos em Ioo possíveis. O poder naval que lhes segue é o do Brasil com 49,5 pontos. Isso significa dizer que existem 49,5 pontos que os separam, porém Isso não significa dizer que a Marinha norte-americana seja o dobro da brasileira. Os pontos que separam os dois poderes navais indicam a distância considerável entre as duas marinhas. Quanto maior a diferença entre pontuações maiores as diferenciações entre os poderes comparados, sem correlação com valores absolutos

Na comparação com o parâmetro “Tipos de Meios Existentes" têm-se uma aproximação com a realidade dos poderes navais, quando comparados entre si na atualidade. Se não vejamos, os valores obtidos pelos EUA nesse parâmetro (Tipo de Meios) chegaram a I758,8. O Brasil obteve I29,8 pontos, isto é quase quatorze vezes menor. Esse parâmetro já demonstra uma valoração próxima da realidade somente considerando os tipos de meios na atualidade. Pode-se até inferir sem grandes correções que a Marinha dos EUA seja quatorze vezes a Armada do Brasil em termos de poder militar. Por meio dessa valoração chega-se a seguinte pontuação das marinhas americanas, considerando apenas os tipos de meios disponíveis: EUA (I758,8 pontos), seguido do Brasil (I29,8), Canadá (II4), Argentina (I03), Peru (97), Chile (77,8), Venezuela (67) ,México (62), Colômbia (48), Equador (44,3), Uruguai ( 18,8$)$, Paraguai (4), Bolívia $(2,5)$. Os demais poderes navais das Américas são inexpressivos e não pontuam.

Os outros parâmetros considerados na metodologia indicam não somente a situação presente entre as marinhas consideradas em termos de números, mas também a capacidade total que determinado país tem em desenvolver o seu poder naval plenamente em comparação com outros poderes, isto é a capacidade disponível potencial para o seu crescimento. Nesse caso tem-se como o primeiro poder naval os EUA com 99 pontos, seguido do Brasil $(49,5)$, Canadá $(48,5)$, México $(45,5)$, Argentina $(43,5)$, Chile $(42)$, Venezuela (40), Colômbia (39), Peru $(38,5)$, Equador $(30,5)$, Uruguai (20), Paraguai (io) e Bolívia $(9,5)$.

Ao comparar-se os dois parâmetros analisados, o "Tipo de Meios" e "Resultado Final" têm-se quase uma coincidência de hierarquização, EUA, Brasil, Canadá, e Argentina, com o México se colocando como potencialmen- 
te mais capacitado a desenvolver o seu poder naval em relação a Argentina, mas menos poderoso na atualidade que esse último. Em seguida despontam cinco países sul-americanos, o Peru, Chile, Venezuela, Colômbia e Equador. O caso do Peru é emblemático, já que no primeiro parâmetro ocupa a quinta colocação, caindo no ranking quando confrontado com a sua capacidade potencial de desenvolver o seu poder naval (nona colocação) com 38,5 pontos. Os demais países analisados se encontram bem afastados desses.

Quanto a classificação quanto a seu alcance os EUA atingem o Nível Io com um Poder Naval com Alcance Global e com Projeção de poder total. Em seguida segue-se o Brasil com o Nível 6, Poder Naval Regional com Projeção de poder parcial na região. O Canadá está inserido no mesmo nível do Brasil com graduação 6. A Argentina, o Chile e o México se colocam no Nível 5 - Poder Naval Regional sem projeção de poder. No nível seguinte o 4 , Poder Naval Local com projeção de poder total em seu território se inserem a Colômbia, o Equador, o Peru e a Venezuela. No Nível 3, Poder Naval Local com projeção de poder parcial em seu território, o Uruguai. Tanto a Bolívia como o Paraguai se colocam no Nível 2, Poder Naval Local sem projeção de poder.

Essa classificação foi baseada em discussões conduzidas pelo Grupo de Controle, composto de oficiais de marinha com ampla experiência em operações no mar, especialistas em estudos do poder marítimo e alunos do Programa de Pós-Graduação em Estudos Marítimos. Ela foi essencialmente uma avaliação qualitativa baseada nas operações conduzidas pelos poderes navais avaliados nos últimos dez anos.

Um dos pontos percebidos foi a deteriorização da Marinha da Venezuela que, a continuar o presente estado de penúria orçamentária, com toda a certeza, cairá no ranking e passará para o Nível 3, Poder Naval Local com projeção de poder parcial em seu território Dois outros poderes navais poderão cair na classificação. Um deles o brasileiro que a continuar as restrições orçamentárias impostas poderá descer para o Nível 5 e o argentino que poderá cair para o nível 4 no mesmo patamar que a Colômbia, Peru e Equador.

Outro ponto percebido é a distância entre a Marinha norte-americana e as demais marinhas americanas. Pode-se prever que nos próximos dez anos haverá um aumento ainda maior nas pontuações comparativas entre os EUA e os demais países e o hiato entre esses poderes navais e o norte-americano será cada vez maior, em razão do nível tecnológico-financeiro dos EUA ser cada vez mais distante dos países americanos.

\section{Considerações Finais}


O propósito principal dessa pesquisa é estabelecer um método o mais próximo possível da realidade para classificar marinhas de guerra no tempo presente. Foram assim estabelecidos onze parâmetros considerados relevantes na avaliação de um poder naval e indicados pesos específicos para cada um desses parâmetros de acordo com sua importância um em relação aos outros. A escolha de cada um desses parâmetros foi produto de amplo debate com especialistas no campo da Segurança e Defesa. Como se pode constatar as decisões de cada um desses fatores e dos pesos foi produto de consenso após ampla deliberação.

Por serem percepções motivadas pela experiência coletiva do Grupo de Controle formado por especialistas e por ser um método comparativo que trafega no campo das Ciências Humanas ele poderá ser aperfeiçoado. Como todo processo desse campo ele poderá ser passível de críticas o que de forma alguma inviabiliza sua aplicação.

A grande novidade nesse processo é que diminui as incertezas motivadas pela percepção de um determinado especialista ou acadêmico de uma classificação baseada tão somente em "sua experiência". Procurou-se assim hierarquizar os poderes navais e estabelecer parâmetros mais confiáveis ao se classificar marinhas, diminuindo sobremaneira a "percepção individual" de cada analista ou acadêmico da área de Defesa.

Para se manter a fiabilidade das informações que são baseadas em fontes ostensivas aplicadas nos onze parâmetros, deve-se continuamente atualizá-las em plataformas de confiabilidade reconhecidas de modo a se manter o resultado final relativo insuspeito.

O anexo constitui a apresentação do modelo para o caso dos poderes navais das Américas, como discutido, dentro de um cenário regional atual com dados extraídos do início de 2018 de fontes fiáveis 


\section{Anexos}

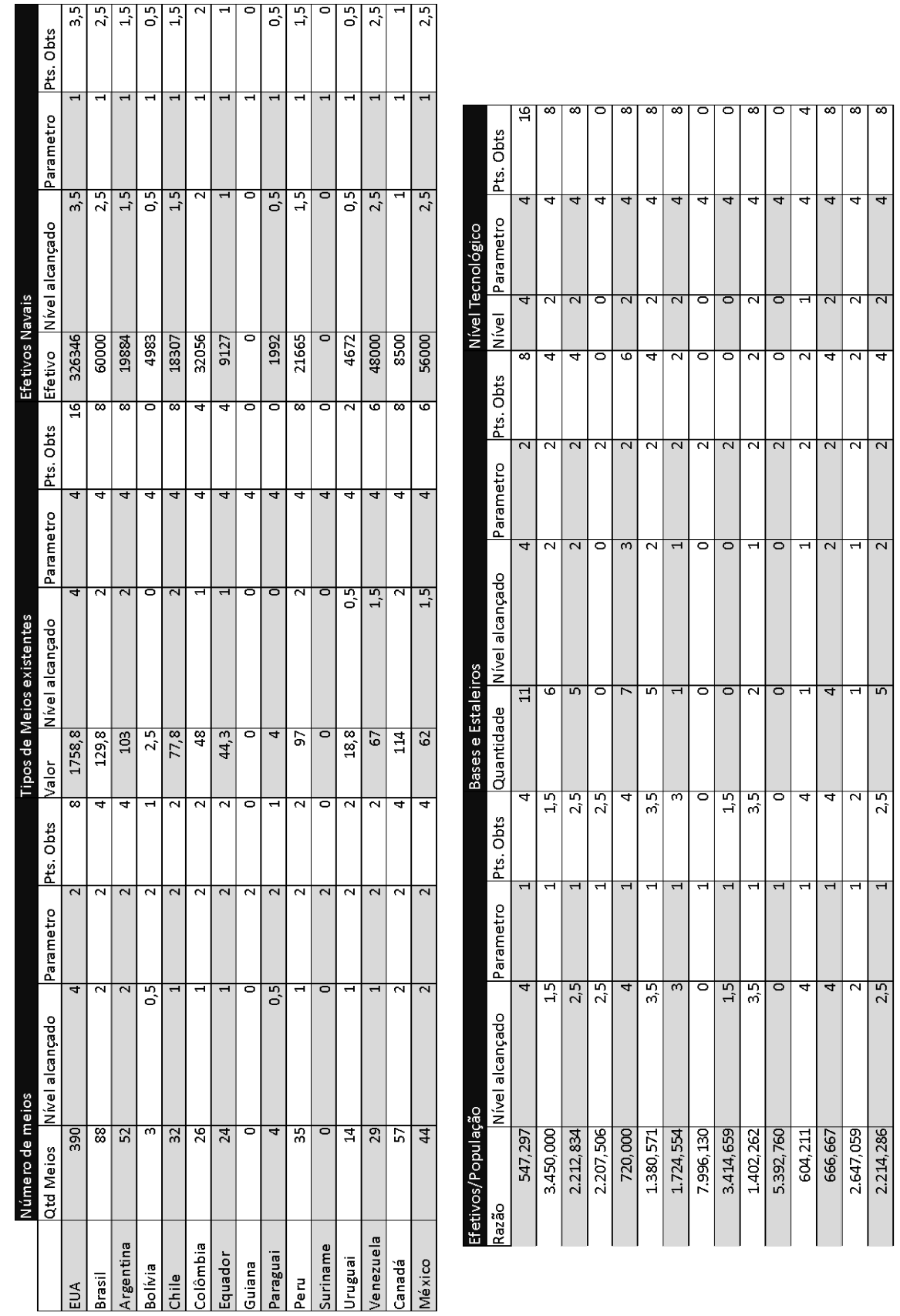

Anexo 1 




Anexo 2 


\section{REFERÊNCIAS}

Coutau-Bégarie, Hervé Coutau. 20ıo. Tratado de Estratégia. Rio de Janeiro: $\mathrm{SDM} / \mathrm{EGN}$.

Grove, Eric. I990. The Future of Sea Power. Annapolis: United States Naval Institute Press.

Mahan, Alfred Thayer. 1983. The Influence of Sea Power upon History 16601783. UK: Dover.

Modelski, George and William Thompson. 1987. Sea Power in Global Politics. United Kingdom: Palgrave MacMillan.

Morris, Michael. I988. Expansion of Third World Navies. Virginia: Palgrave MacMillan.

Till, Geoffrey. 2009. Sea Power. A Guide for the 21st Century. 2ed. United Kingdom: Routledge.

\section{RESUMO}

A classificação de marinhas, segundo o seu poder relativo, tem sido um desafio para a área acadêmica que trabalha com temas no campo da Segurança e da Defesa. Classificações qualitativas têm sido apresentadas por pesquisadores do porte de Colin Gray, Hervé Coutau-Begarie e Michael Morris, no entanto essas tentativas têm esbarrado em sua simplicidade e pouca abrangência. A partir de estudos baseados em fontes de acesso aberto procurou-se estabelecer uma metodologia comparativa que não só levasse em consideração fatores qualitativos mas também quantitativos. Procurou-se com esse método inovador classificar as marinhas de guerra dos diferentes Estados em um ranking de poder levando-se em consideração parâmetros como o número de meios, capacidade de construção naval, quantidade de bases e arsenais, efetivos navais e disponibilidade de recursos, dentre alguns, de modo a hierarquizar esses poderes navais. Essa metodologia pretende diminuir as incertezas na classificação de marinhas e servir de referência para futuros trabalhos na área acadêmica que se dedicam aos campos de Segurança e Defesa.

\section{PALAVRAS-CHAVE}

Metodologia; Estudos Marítimos; Marinhas de Guerra. 